\title{
Nucleotide variants and protein expression of TP53 in a Sri Lankan cohort of patients with head and neck cancer
}

\author{
VAHINIPRIYA MANOHARAN ${ }^{1}$, ERIC HAMILTON KARUNANAYAKE ${ }^{1}$, KAMANI HEMAMALA TENNEKOON ${ }^{1}$, \\ SUMADEE DE SILVA $^{1}$, KANISHKA DE SILVA ${ }^{2}$, PREETHIKA ANGUNAWELA ${ }^{3}$ and JOHN LUNEC ${ }^{4}$ \\ ${ }^{1}$ Institute of Biochemistry, Molecular Biology and Biotechnology, University of Colombo, Colombo 00300; \\ ${ }^{2}$ Department of Oncosurgery, National Cancer Institute, Maharagama 10280; \\ ${ }^{3}$ Department of Pathology, Faculty of Medicine, University of Colombo, Colombo 00800, Sri Lanka; \\ ${ }^{4}$ Northern Institute for Cancer Research, Newcastle University, Newcastle NE2 4AD, UK
}

Received August 16, 2018; Accepted January 30, 2019

DOI: $10.3892 / \mathrm{mmr} .2019 .9948$

\begin{abstract}
Head and neck cancer (HNC) is the leading cancer in Sri Lankan males and second most common cancer among Sri Lankan females. This is the first study, to the best of our knowledge, that has focused on investigating the association between TP53 somatic DNA variants, with p53 protein expression and risk factors in a cohort of Sri Lankan patients with HNC. A total of 44 patients with cancer and 20 healthy controls were studied. In total, 36 genomic DNA sequence variants were found, including several novel variants (two deletions in exons 4 and 6, two in the $3^{\prime}$ untranslated region and several intronic variants). A total of 14 tumour samples carried pathogenic TP53 mutations. A random selection of 24 samples was analysed immunohistochemically for p53 protein expression. All the samples with point missense variants were strongly immuno-positive, whereas, samples with nonsense and frameshift TP53 variants were immuno-negative for p53 immunohistochemical staining. Although, the human papilloma virus is a known risk factor for HNC, results from the present study identified an absence or lower level of infection in the Sri Lankan cohort.
\end{abstract}

\section{Introduction}

Head and neck cancer (HNC) is a broad spectrum of disease that encompasses malignancies in the aero-digestive tract,

Correspondence to: Dr Sumadee De Silva, Institute of Biochemistry, Molecular Biology and Biotechnology, University of Colombo, 90 Cumaratunga Munidasa Mawatha, Colombo 00300, Sri Lanka E-mail:sum@ibmbb.cmb.ac.lk

Abbreviations: DNE, dominant negative effect; HNC, head and neck cancer; HPV, human papilloma virus; IHC, immunohistochemistry; PCR, polymerase chain reaction; UTR, untranslated region

Key words: HNC, TP53, nucleotide sequencing, IHC, risk factors, Sri Lankan population including the oral cavity, pharynx, larynx, nasal cavity, paranasal sinuses, salivary glands, thyroid and parathyroid glands (1). HNC is the sixth most common cancer worldwide. Sri Lanka is considered as one of the high-risk countries, where HNCs are the leading cancer type in men accounting for $29 \%$ of all cancers (2-4).

Cigarette smoking and alcohol consumption, which are considered to be the most common risk factors for HNC, are generally lower in Sri Lankans compared to Western populations $(2,5)$. However, tobacco chewing and consumption of areca nut are considered to be the most common causes of HNC in Sri Lankan males (3,5-7). Tobacco chewing results in exposure to 28 known carcinogens, including the non-volatile alkaloid-derived tobacco-specific N-nitrosamine and $\mathrm{N}$-nitrosamino acids, which are different from the carcinogens involved in smoking cigarettes $(3,8)$. The high risk associated with human papilloma virus (HPV) infection for specific types of HNCs is well established and studied in different geographical areas (9). However there is a scarcity of literature available on HPV associated HNC in the Sri Lankan population.

p53 acts as a 'guardian of the genome' to maintain the balance of cell death and proliferation by regulating the cell cycle, DNA repair, apoptosis, cellular metabolism and senescence (10). It is altered in $~ 50 \%$ of cancers overall and is more frequent in adult vs. childhood malignancies (11). The efficacy of many cancer therapeutic approaches is influenced by the functional status of the p53 tumour suppressor protein. Thus identification of TP53 mutation status prior to administration of therapy can predict potential effectiveness of the treatment and influence treatment selection. Furthermore, the TP53 mutation spectrum provides information on tumour origin, cause of mutation, aetiology, molecular pathogenesis, prediction of patient survival and chances of recurrence (12-15).

There were numerous studies on TP53 variants in various cancers including head and neck cancer over the last few decades, particularly in Western populations. But there are only few studies done considering all subsets of HNC in Asia including India (16) and Japan (17) excluding Sri Lanka. Since the frequency of TP53 mutations and the mutation spectra vary in different geographic areas, according to 
aetiological factors, life style, dietary pattern and culture, the present study has focused on establishing the TP53 mutation spectrum in Sri Lankan HNC patients. Furthermore we used immunohistochemistry (IHC) to assess p53 protein expression and correlated immuno-expression of p53 with TP53 gene mutational status. We also studied HPV infection in HNC and oesophageal cancer using p16 immuno-expression and HPV DNA detection, as the latter has reported to be associated with oral cancer in Sri Lankan patients (18).

\section{Materials and methods}

Patient recruitment and sample processing. Ethical approval was obtained from the Ethics Review Committee, Faculty of Medicine, University of Colombo, Sri Lanka (EC/14/160). Patients with HNC ( $=44)$ who had undergone surgical resection at the National Cancer Institute, Sri Lanka, were recruited for this study. Written informed consent from the study participants was obtained prior to recruitment. Socio-demographic and clinical data were obtained from study participants using questionnaires and by reviewing their medical reports. The majority of our patient population represents the Sinhalese ethnicity. Healthy controls ( $N=20 ; 10$ males, 10 females) with no personal/family history of any cancer were recruited for this study.

Surgically excised tumour tissues were collected and the close adjacent region of the tissue section was placed in $10 \%$ formalin to prepare Formalin Fixed Paraffin Embedded tissue while the other section was immediately placed in Allprotect ${ }^{\circledR}$ Tissue Reagent (cat no. 76405; Qiagen, Hilden, Germany) and stored at $-20^{\circ} \mathrm{C}$ until processed. The hematoxylin and eosin stained slides of each tissue were reviewed by a pathologist to confirm the percentage of tumour region. Studied samples were with $>50 \%$ area coverage of tumour in the study, except only two samples had $<10 \%$ of tumour cells in the sections.

Genomic DNA was extracted from the excised tumour tissue of patients and from peripheral venous blood of healthy controls. Disruption of tissue specimens was done in liquid nitrogen using a motor and pestle followed by homogenization using QIAshredder (cat. no. 79654; Qiagen). Tissue DNA was extracted from homogenized sample using an All prep DNA/RNA/Protein mini kit (cat. no. 80004; Qiagen) following the manufacturer's protocol and stored at $-20^{\circ} \mathrm{C}$ until used. Genomic DNA was extracted from blood using the modified protocol described by Miller et al (19).

Seven sets of primers covering the entire exon 2-11 coding regions and adjacent flanking $5^{\prime}$ and $3^{\prime}$ intronic regions were designed using the online NCBI/Primer-BLAST software (https://www.ncbi.nlm.nih.gov/tools/primerblast/index. cgi?ORGANISM=9606\&INPUT_SEQUENCE=NM_001618.3). Polymerase Chain Reaction (PCR) amplification was performed using each primer set in a final volume of $25 \mu \mathrm{l}$ containing $100 \mathrm{ng}$ genomic DNA, $3.5 \mathrm{mM} \mathrm{MgCl} 2$, $1 \mathrm{X}$ Green GoTaq $^{\circledR}$ reaction buffer $[10 \mathrm{mM}$ Tris- $\mathrm{HCl}(\mathrm{pH} 8.3)$ and $50 \mathrm{mM}$ $\mathrm{KCl}$ ], $2.5 \mathrm{mM}$ dNTPs (Promega Corporation, Madison, WI, USA), 5 pmols of each primer (IDT Integrated DNA Technologies, Coralville, IA, USA) and 1 unit of GoTaq ${ }^{\circledR}$ Flexi DNA polymerase (Promega Corporation). PCR conditions: $94^{\circ} \mathrm{C}$ for $7 \mathrm{~min}$, followed by 33 cycles of $94^{\circ} \mathrm{C}$ for $1 \mathrm{~min}$, at the optimized annealing temperature for $1 \mathrm{~min}$ and $72^{\circ} \mathrm{C}$ for $1 \mathrm{~min}$ and a final extension step of $72^{\circ} \mathrm{C}$ for 10 min was performed in a thermocycler (Veriti Thermal Cycler; Thermo Fisher Scientific, Waltham, MA USA). The annealing temperature and $\mathrm{MgCl}_{2}$ concentration were optimized for each primer set. The primer nucleotide sequences, amplicon sizes and annealing temperatures are shown in Table I.

PCR products were purified using the Wizard ${ }^{\circledR} \mathrm{SV}$ Gel and PCR Clean-Up kit (Promega Corporation) and purified products were directly sequenced using the BigDye ${ }^{\circledR}$ Terminator v3.1 kit (Thermo Fisher Scientific) and an Applied Biosystems ${ }^{\mathrm{TM}}$ 3500Dx Genetic Analyzer (Thermo Fisher Scientific). Sequence variants detected were reconfirmed by performing a second PCR and direct sequencing.

Sequencing results were analysed to identify variants by alignment with a human TP53 NCBI reference sequence (GenBank accession number-NC_000017), via Bio Edit ${ }^{\circledR}$ software and further confirmed by Mutation Surveyor ${ }^{\circledR}$ v4.0.9 and Alamut ${ }^{\circledR}$ Visual 2.7.2 Documentation. Identified sequence variants were named according to the Human Genome Variation Society/HGVS nomenclature guidelines (http://www.hgvs. org/mutnomen/).

Variant analysis. Identified sequence variants were checked for previous reports in the following databases: Catalogue Of Somatic Mutations in Cancer (COSMIC) (http://cancer. sanger.ac.uk/cosmic); NCBI (https:/www.ncbi.nlm.nih.gov/); IARC TP53 (http://p53.iarc.fr/); Ensembl (https://asia.ensembl. org/index.html); the p53 website (https://p53.fr/tp53-database).

Pathogenicity of the identified exonic variants was analysed using five comparative missense prediction programs: Align GVGD (http://agvgd.hci.utah.edu/agvgd_input. php); SIFT (http://sift.jcvi.org/www/SIFT_seq_submit2. html); MutationTaster (http://www.mutationtaster.org/); PolyPhen-2 (http://genetics.bwh.harvard.edu/pph2/); Provean (http://provean.jcvi.org/seq_submit.php). p53 specific structural and functional activity (transcriptional activity, dominant negative effect) data available on IARC TP53 database was also considered while determining the pathogenicity of the identified variants $(18,19)$. Human Splicing Finder V3.0 (http://www.umd.be/HSF3/) and splicing window of Alamut ${ }^{\circledR}$ Visual software, integrating a number of prediction methods (for splice signal detection: MaxEntScan, GeneSplicer and ESE/exonic splicing enhancer binding site detection: ESEFinder, RESCUE-ESE) were used to assess the impact on gene splicing of identified intronic variants. All variants were classified according to American College of Medical Genetics standards and guidelines (20).

Immunohistochemistry for p53. IHC characterization of $\mathrm{p} 53$ expression was performed on twenty four randomly selected representative formalin fixed paraffin-embedded tumour tissue sections. The primary antibody used was mouse monoclonal Anti-Human p53 clone DO-7 (Agilent DaKo, Santa Clara, USA) at 1:100 dilution. Tissue sections of 4 micron thickness were mounted on microscopic slides and dried at $60^{\circ} \mathrm{C}$ for $2 \mathrm{~h}$. After dewaxing in xylene, sections were rehydrated in graded $(100,95,70$ and 60\%) alcohol. Microwave heating in citrate (pH 6) buffer was used for antigen retrieval and endogenous peroxidase was inhibited by incubating tissue sections in freshly prepared $3 \%$ hydrogen peroxide. Tissue sections were 
Table I. Nucleotide sequence of primers used for amplification of TP53, amplicon size and annealing temperature.

\begin{tabular}{|c|c|c|c|}
\hline Exon & $\begin{array}{l}\text { Primer sequence, } \\
5^{\prime}-3^{\prime}\end{array}$ & $\begin{array}{l}\text { Amplicon } \\
\text { size } \\
\text { (bp) }\end{array}$ & $\begin{array}{c}\text { Annealing } \\
\text { temperature } \\
\left({ }^{\circ} \mathrm{C}\right)\end{array}$ \\
\hline 2 and 3 & $\begin{array}{l}\text { CAGCCATTCTTTTCCTGCTC } \\
\text { GGGGACTGTAGATGGGTGAA }\end{array}$ & 497 & 62 \\
\hline 4 & $\begin{array}{l}\text { CCTGGTCCTCTGACTGCTCT } \\
\text { GCCAGGCATTGAAGTCTCAT }\end{array}$ & 361 & 64 \\
\hline 5 and 6 & $\begin{array}{l}\text { GTTTCTTTGCTGCCGTCTTC } \\
\text { CTTAACCCCTCCTCCCAGAG }\end{array}$ & 500 & 64 \\
\hline 7 & $\begin{array}{l}\text { GAGCTTGCAGTGAGCTGAGA } \\
\text { TCCCAAAGCCAGAGAAAAGA }\end{array}$ & 444 & 63 \\
\hline 8 and 9 & $\begin{array}{l}\text { CAAGGGTGGTTGGGAGTAGA } \\
\text { TGTCTTTGAGGCATCACTGC }\end{array}$ & 532 & 65 \\
\hline 10 & $\begin{array}{l}\text { TGCATGTTGCTTTTGTACCG } \\
\text { GAAGGCAGGATGAGAATGGA }\end{array}$ & 299 & 56 \\
\hline 11 & $\begin{array}{l}\text { TGTCATCTCTCСТСССТGCT } \\
\text { AAGTGGGCCCCTACCTAGAA }\end{array}$ & 438 & 61 \\
\hline
\end{tabular}

incubated with primary antibody at room temperature for an hour and then exposed to horseradish peroxidase (A. Menarini Diagnostics Ltd., Winnersh, UK) conjugated anti-mouse IgG secondary antibody for $30 \mathrm{~min}$. Universal probe (A. Menarini Diagnostics Ltd.) was applied for $30 \mathrm{~min}$ before the addition of primary antibody, in order to increase the staining sensitivity 10 to 40 times for mouse monoclonal antibodies. Then, the slides were incubated with 3,3'-diaminobenzidine (A. Menarini Diagnostics Ltd.). Following the incubation, the sections were washed and counter stained with haematoxylin. Slides that were not incubated in primary antibody were used as antibody negative controls to check for specificity of staining.

Images of the stained slides were visualized using the AperioScanScope ${ }^{\circledR}$ CS System, an automated digital scanner (Aperio Technologies, Bristol, UK) technology and Spectrum $^{\text {TM }}$ image management software. The slides were analysed by both automated and manual methods, blinded from the clinical data.

Human papilloma virus DNA screening. PCR with $\mathrm{GP}^{+} / \mathrm{GP}^{+} \mathrm{HPV}$ specific primers was performed for all $\mathrm{HNC}$ samples in a final volume of $25 \mu \mathrm{l}$ containing 100-150 ng genomic DNA, $3.5 \mathrm{mM} \mathrm{MgCl}{ }_{2}$, $1 \mathrm{X}$ Green $\mathrm{GoTaq}^{\circledR}$ reaction buffer [10 mM Tris- $\mathrm{HCl}(\mathrm{pH} 8.3)$ and $50 \mathrm{mM} \mathrm{KCl}], 2.5 \mathrm{mM}$ dNTPs (Promega Corporation), 50 pmols of each primer (IDT Integrated DNA Technologies) and 1 unit of GoTaq ${ }^{\circledR}$ Flexi DNA polymerase (Promega Corporation). PCR conditions: $94^{\circ} \mathrm{C}$ for $4 \mathrm{~min}$, followed by 40 cycles of $94^{\circ} \mathrm{C}$ for $1 \mathrm{~min}, 40^{\circ} \mathrm{C}$ for $1 \mathrm{~min}$ and $72^{\circ} \mathrm{C}$ for $1 \mathrm{~min}$ and a final extension step at $72^{\circ} \mathrm{C}$ for $10 \mathrm{~min}$ (21). The negative control included all reagents except for DNA. A p1203 PML2d HPV-16 plasmid (gift from Peter Howley: Addgene plasmid \#10869) was used as the positive control. Samples positive for HPV generate a 140-bp-long fragment from the HPV L1 structural gene. p16 immunohistochemistry. p16 cyclin-dependent kinase inhibitor protein expression was detected using IHC at the pathology laboratory of the Royal Victoria Infirmary, Newcastle upon Tyne using a Ventana Benchmark XT Automated IHC/In situ hybridization slide staining system (Ventana Medical Systems, Inc., Tucson, AZ, USA). The CINtec ${ }^{\circledR}$ p16 Histology (Hoffmann-La Roche AG, Basel, Switzerland) and UltraView DAB detection kit (Ventana Medical Systems Inc.) were used for the detection of p16. Images of the stained slides were visualized and analysed using the same process as for p53 detection.

Patient follow-up. Data on response to treatment, survival, recurrence and current status during the follow-up period were collected by reviewing patient medical records and collecting data directly from patients/guardians.

Statistical analysis. All categorical data were analysed using Fisher's exact test to assess the significance of the associations. A P-value $<0.05$ was considered as statistically significant.

\section{Results}

Baseline characteristics of participants. Out of the 44 patients, $75 \%(\mathrm{~N}=33)$ were males and $25 \%(\mathrm{~N}=11)$ were females. Mean \pm SD age was $59.03 \pm 11.68$ years for males and 53.27 \pm 19.04 years for females. Healthy controls were younger (males $33.2 \pm 4.92$; females $33.1 \pm 5.84$ years). Table II summarizes the characteristics of the patients, tumour type and possible risk factors the patients were exposed to.

Analysis of TP53 sequence variants and epidemiological/clinical correlations. A total of 36 sequence variants (18 translated exonic variants, 12 intronic and 2 non-translated exonic variants) were found in 44 patients and 4 additional sequence variants were found only in healthy controls (two exonic silent and two novel intronic variants). Table III illustrates the characteristics, In silico and functional analysis of each variant. All the exonic variants were in the DNA binding domain of the p53 protein (codons 94-292).

c. $298 \mathrm{delC} / \mathrm{p}$. Gln100Argfs $* 23$, a novel heterozygous frameshift variant in exon 4 that created a stop codon at position 123, was found in a male patient with upper oesophageal cancer (Fig. 1) diagnosed at 51 years of age. A c. $383 \mathrm{delC} / \mathrm{p}$. Pro128Leufs*42 frameshift variant in exon 5 that created a stop codon at position 170 was also found in a male patient with cancer recurrence in the vocal cord.

A novel 12 base pair in-frame deletion in exon 6 (c.626_637delGAAACACTTTTC/p.Asn210_Arg213del), that would results in the loss of 4 amino acid residues from 210 to 213, producing a 389 amino acid protein (Fig. 2) was detected in the tumour DNA of a 61-year-old male patient with oesophageal cancer.

Another male patient with recurrent cheek cancer had one nonsense pathogenic variant, c.493C > T (p.Gln165*) in exon 5, creating a stop codon at position 165 , together with a pathogenic missense variant (c.578A $>$ G/p.His193Arg) in exon 6 and survived only two years and eight months following recurrence. A c.637C $>\mathrm{T}$ (p.Arg213*) a nonsense pathogenic variant in exon 6 , creating a stop codon at 213 position was 
Table II. Baseline characteristics of the patients, tumour type and possible risk factors the patients were exposed to.

\begin{tabular}{|c|c|c|c|c|c|}
\hline Characteristics & $\begin{array}{c}\text { Total number } \\
\text { of patients }\end{array}$ & $\begin{array}{c}\text { Patients with } \\
\text { wild-type } T P 53, \text { no. }\end{array}$ & $\begin{array}{c}\text { Patients with } \\
\text { mutated TP53, no. }\end{array}$ & $\begin{array}{c}\text { Total number } \\
\text { of healthy controls }\end{array}$ & $\begin{array}{l}\text { Two-tailed P-value } \\
\text { between patient } \\
\text { and healthy controls }\end{array}$ \\
\hline \multicolumn{6}{|l|}{ Sex } \\
\hline Male & 33 & 23 & 10 & 10 & 0.1176 \\
\hline Female & 11 & 7 & 4 & 10 & \\
\hline \multicolumn{6}{|l|}{ Ethnicity } \\
\hline Sinhalese & 35 & 23 & 12 & 13 & 0.0888 \\
\hline Sri Lankan Tamil & 3 & 3 & 0 & 5 & \\
\hline Indian Tamil & 3 & 1 & 2 & 1 & \\
\hline Muslims & 3 & 3 & 0 & 0 & \\
\hline Burghers & 0 & 0 & 0 & 1 & \\
\hline \multicolumn{6}{|l|}{ Age at study entry } \\
\hline$<30$ years & 2 & 2 & 0 & 2 & 0.0007 \\
\hline $30-60$ years & 24 & 14 & 10 & 18 & \\
\hline$>61$ years & 18 & 14 & 4 & 0 & \\
\hline \multicolumn{6}{|l|}{ Tumour type } \\
\hline Squamous cell carcinoma & 25 & 13 & 12 & N/A & N/A \\
\hline Adenocarcinoma & 4 & 3 & 1 & N/A & \\
\hline Papillary carcinoma & 4 & 4 & 0 & N/A & \\
\hline Others & 11 & 10 & 1 & N/A & \\
\hline \multicolumn{6}{|l|}{ Smoking history } \\
\hline Yes & 17 & 11 & 6 & 0 & 0.0005 \\
\hline No & 25 & 17 & 8 & 20 & \\
\hline Unknown & 2 & 2 & 0 & 0 & \\
\hline \multicolumn{6}{|l|}{ Alcohol consumption } \\
\hline Yes & 13 & 8 & 5 & 1 & 0.0251 \\
\hline No & 29 & 20 & 9 & 19 & \\
\hline Unknown & 2 & 2 & 0 & 0 & \\
\hline \multicolumn{6}{|l|}{ Betel-quid chewing } \\
\hline Yes with tobacco & 21 & 12 & 9 & 0 & $<0.0001$ \\
\hline Yes without tobacco & 2 & 2 & 0 & 0 & \\
\hline No & 19 & 14 & 5 & 20 & \\
\hline Unknown & 2 & 2 & 0 & 0 & \\
\hline \multicolumn{6}{|l|}{ Roofing } \\
\hline Asbestos & 21 & 14 & 7 & 1 & $<0.0001$ \\
\hline Tile & 15 & 11 & 4 & 5 & \\
\hline Concrete & 1 & 1 & 0 & 12 & \\
\hline Metal & 3 & 2 & 1 & 0 & \\
\hline Unknown & 4 & 2 & 2 & 2 & \\
\hline Codon 72 polymorphism & & & & & 0.6225 \\
\hline Arginine & 10 & 6 & 4 & 7 & \\
\hline Proline & 19 & 12 & 7 & 7 & \\
\hline Arginine/proline & 15 & 12 & 3 & 6 & \\
\hline
\end{tabular}

aFisher's exact test was done to examine the significance of the associations between patients and healthy controls. A P-value $<0.05$ was considered as statistically significant.

observed in a 72-year-old male patient with tumour of the mandible.

A 59-year-old female patient with a malignancy in the cheek carried two variants in exon 5; a pathogenic missense variant (c.422G >T/p.Cys141Phe) and a likely-pathogenic missense variant (c.467G >A/p.Arg156His). She survived for one year and eight months following diagnosis.
Another 59-year-old male patient had a cancer diagnosed in 2010 in the retro molar region which recurred in the mandible after 5 years. He had a single pathogenic missense variant, c. $455 \mathrm{C}>\mathrm{T} / \mathrm{p}$.Pro152Leu in exon 5. Another pathogenic variant, c. $524 \mathrm{G}>\mathrm{A} / \mathrm{p}$.Arg175His in exon 5 was observed in a male patient with left antral malignancy and in a female patient with oesophageal cancer. 


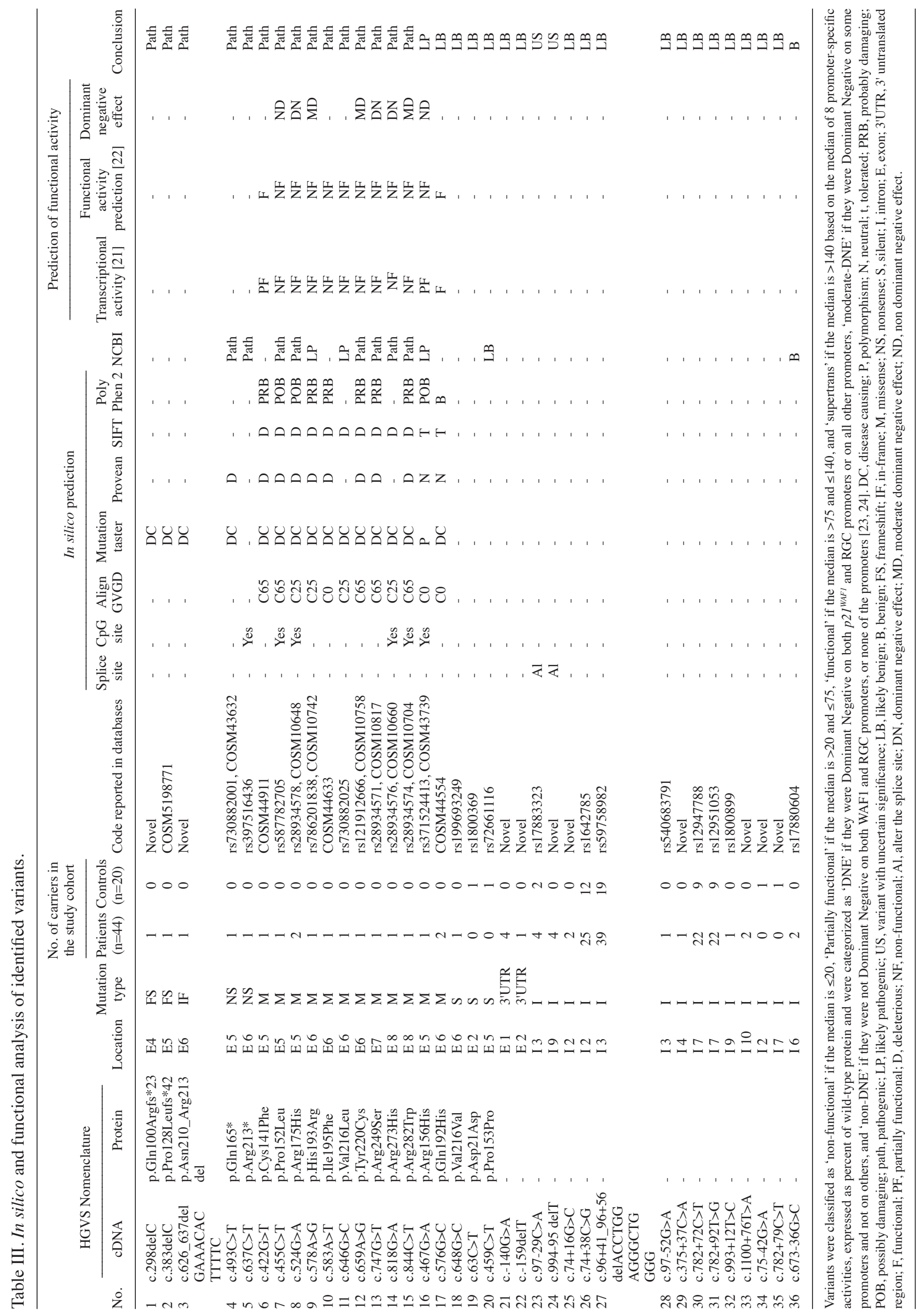


A $R \rightarrow$ TP53 sequence___Synthesis_11443.scf- $\rightarrow \quad$ Quality(0-100):64

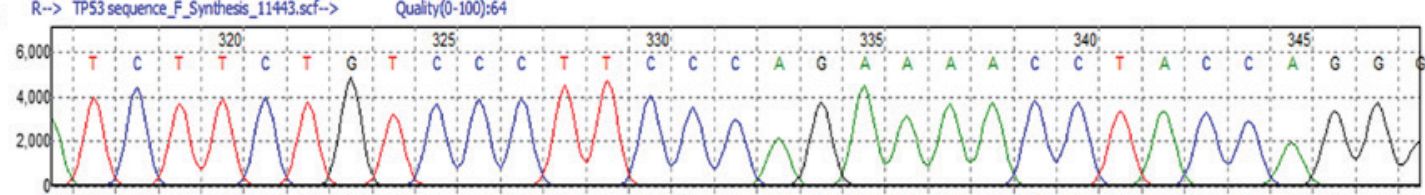

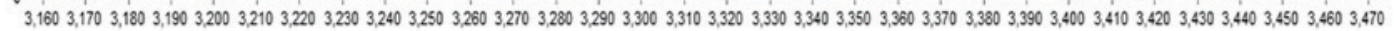

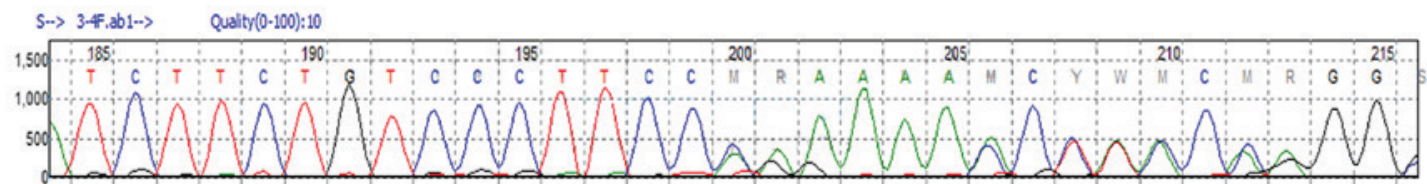

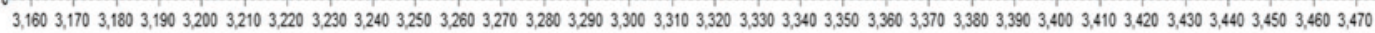

B

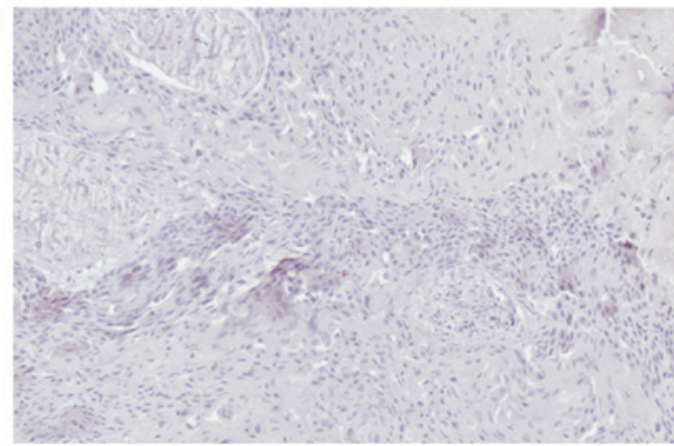

C

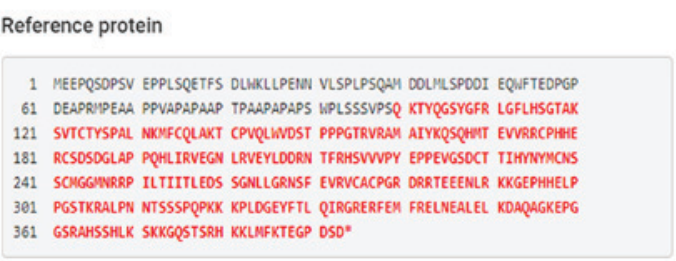

\section{Protein predicted from variant coding sequence}

1 MEEPQSOPSV EPPLSQETFS DLAKLLPEIW VLSPLPSQM DOLMLSPOOI EQWFTEDPGP

61 DEAPRMPEAA PPVAPAPAAP TPAAPAPAPS UPLSSSVPSR KPTRAATVSV MASCILGQPS

$121 \mathrm{~L}^{*}$

Figure 1. Novel frameshift variant c.298delC/p.Gln100Argfs*23 detected in Exon 4. (A) Mutation Surveyor ${ }^{\oplus}$ V4.0.9 image indicating the one base pair heterozygous deletion point; R indicates the reference TP53 sequence and S indicates the study sample TP53 sequence. (B) p53 immunohistochemical staining of the tumour sample with the above mutation. Magnification, x20. (C) Protein prediction using Mutalyzer 2.0.26.

A $R \rightarrow$ TP53 sequence___Synthesis_12503.sff $\rightarrow$ Quality(0-100):90

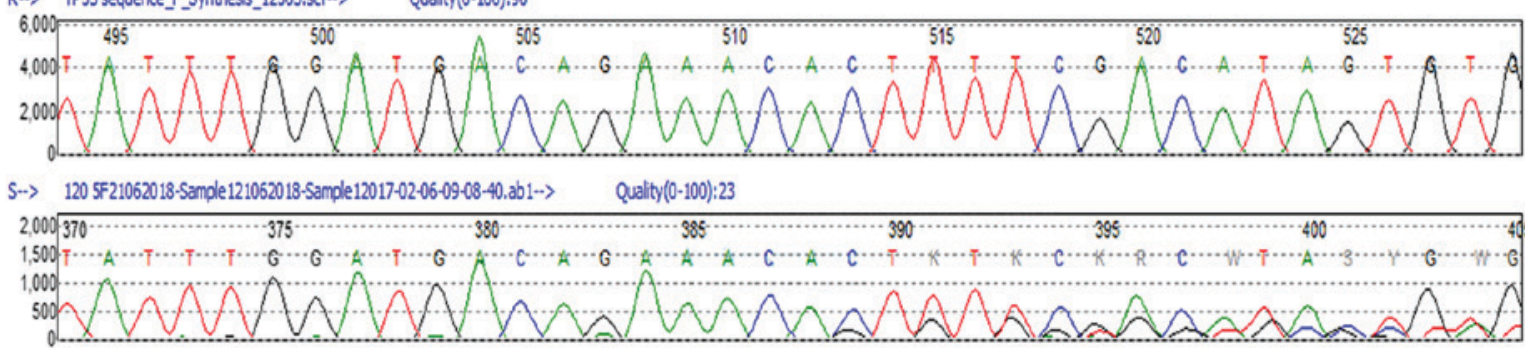

B

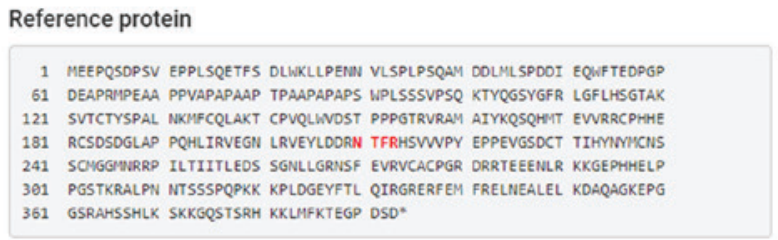

\section{Protein predicted from variant coding sequence}

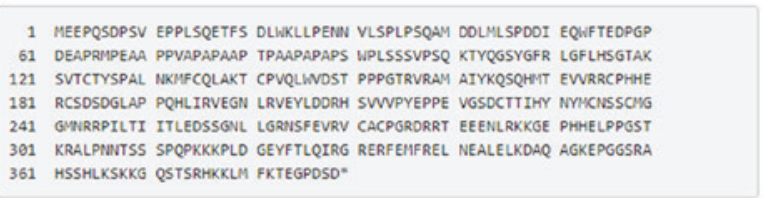

Figure 2. Novel in-frame deletion c.626_637delGAAACACTTTTC/p.Asn210_Arg213del detected in exon 6. (A) Mutation Surveyor ${ }^{\circledR}$ V4.0.9 image indicating the 12-base pair heterozygous deletion; $\mathrm{R}$ indicates the reference TP53 sequence and $\mathrm{S}$ indicates the study sample TP53 sequence. (B) Protein prediction using Mutalyzer 2.0.26.

Four pathogenic missense variants were detected in exon 6 (c.583A>T, c.659A >G, c.646G >C , c.578A $>$ G). One male patient aged 59 diagnosed with upper oesophageal cancer had a c.583A $>$ T/p.Ile195Phe variant. A c.659A $>$ G/p.Tyr220Cys variant was found in a 55-year-old male patient with malignancy in the retro molar region. This variant co-existed with another pathogenic variant, c. $818 \mathrm{G}>\mathrm{A} / \mathrm{p} . \mathrm{Arg} 273 \mathrm{His}$, in exon 8 . Co-existence of c.646G $>C$ and c.648G $>C$ (p.Val216Leu) variants were identified in the malignant cheek tumour of a 60-year-old female patient. 

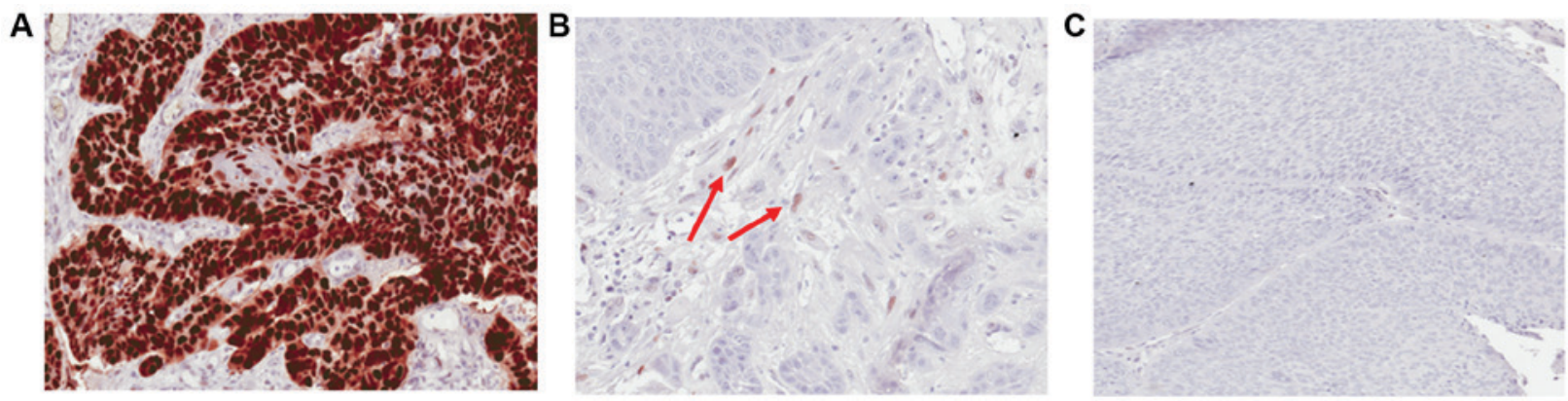

Figure 3. IHC characterization of p53 detected by DO7 antibody. (A) Pattern A with wide spread IHC positive nuclei-IHC score $>20$. (B) Pattern B with rare positive single tumour nuclei-IHC score from $\geq 1$ to $\leq 20$; arrows indicate the rare positive cells. (C) Pattern $\mathrm{C}$ with no IHC positive nuclei-IHC score from 0 to $<1$. Magnification, x20. IHC, immunohistochemistry.

c.576G $>$ C/p.Gln192His, a likely-benign variant was identified in exon 6 in a 68-year-old female patient with oesophageal cancer and in a male patient with arytenoid cartilage cancer. The only pathogenic missense variant c.747G $>$ T/p.Arg249Ser in exon 7 was observed in a male patient aged 68 years with cancer in the cheek.

A c. $844 \mathrm{C}>\mathrm{T} / \mathrm{p}$. $\operatorname{Arg} 282 \mathrm{Trp}$ variant in exon 8 was found in a 60 -year-old female patient with a mandible cancer who survived only 1 year and 5 months following diagnosis.

Among the 14 patients who had pathogenic variants, eight had a history of betel quid-tobacco chewing, five in the absence of smoking or alcoholism and three in the presence of smoking and alcoholism. Six of the patients with pathogenic variants did not have a history of betel quid-tobacco chewing, but three of them were smokers and had a history of alcoholism.

Among the intronic variants, c.994-95delT, a novel deletion in intron 9 was identified in 4 patients but not in controls and c. $97-29 \mathrm{C}>\mathrm{A}$, a reported variant substitution in intron 3 , which was identified in four patients and in two controls were categorized as variants with uncertain significance as both alter the WT branch point and potentially alter the splicing according to Human Splicing finder.

Two novel variants were found in the 5'UTR of the gene; c. $-140 \mathrm{G}>\mathrm{A}(\mathrm{N}=4)$ and c.-159delT $(\mathrm{N}=1)$ in patients but not in healthy controls. Three more novel intronic variants were found in patients $[\mathrm{c} .74+16 \mathrm{G}>\mathrm{C}(\mathrm{N}=2)$, c. $375+37 \mathrm{C}>\mathrm{A}(\mathrm{N}=1), \mathrm{c} .1100+76 \mathrm{~T}>\mathrm{A}(\mathrm{N}=2)]$ in introns 2 , 4 and 10 respectively but not in any healthy controls. In contrast, two other novel variants [c.75-42G $>$ A (intron 2) and c.782+79C $>\mathrm{T}$ (intron 7)] were observed in healthy controls but not in patients.

TP53 gene status and expression of p53 protein. Twenty four samples were randomly chosen for IHC analysis. The H-Score for each slide was calculated by multiplying the intensity of staining (no staining, 0 ; weak, 1; intermediate, 2; and strong, 3) by the percentage of cells at each staining intensity level. Scores ranged from 0 to 300 . Scores were grouped into three categories; from 0 to $<1$ was considered negative (Pattern-C), score ranging from 1 to 20 (Pattern-B) and all the scores $>20$ (Pattern-A) (Fig. 3).

IHC staining for $\mathrm{p} 53$ showed positive immuno-reactivity in 13/24 (54.17\%) cases. Nine of these tumours showed widespread IHC positive tumour nuclear staining involving either the entire tissue section or a segment of it (Pattern-A) while
4 showed rare/scattered p53 positive single tumour nuclei (Pattern-B). All cases with a missense variant in TP53 gene showed Pattern-A IHC staining. However, vice versa is not true because 2 cases showed IHC positivity with Pattern-A in the absence of detectable pathogenic TP53 gene variants. These had only $\sim 10 \%$ of positively stained tumour cells in the respective tissue sections. One case with both missense and nonsense variants showed Pattern-A IHC staining. All 4 cases with Pattern-B IHC staining had no detectable pathogenic TP53 variants. Among the 11 cases with immuno-negativity (Pattern-C), two had frameshift variants and one had a nonsense variant. The remaining eight patients who showed immuno-negativity had wild-type TP53.

Prevalence of $\mathrm{HPV}$. Sensitivity of the $\mathrm{GP}^{+} / \mathrm{GP}^{+}$primer pair was at the level of femtograms for HPV genotypes which match strongly with the primers and at the level of picograms for HPV genotypes having four or more mismatches to the primers (21). Absence of positive results in our study cohort indicated either absence of HPV DNA or the presence of HPV DNA at a concentration below the level of sensitivity.

The IHC staining for p16 is defined as positive if there is strong and diffuse nuclear and cytoplasmic staining pattern in $>70 \%$ of the tumour specimen (Fig. 4). Regardless of cancer type, TP53 mutation status and p53 protein expression, all HNC samples in the Sri Lankan study cohort were negative for p16 staining, despite clear positive staining with the control sample.

\section{Discussion}

This is a preliminary study on Sri Lankan HNC patients, focused on the mutation spectrum of the TP53 gene, expression of p53 protein and relationship to possible risk factors. In the present study, we also included upper oesophageal cancer, as HNCs are often associated with oesophageal cancer and both tumour types share common risk factors (22).

Identification of hotspot regions of TP53 mutations in the Sri Lankan context is useful to prioritize screening of such regions rather screening the entire gene, prior to treatment. In the current study, $70 \%$ (11 out of 15) of pathogenic mutations reported were detected in the exon 5 and 6 which is covered by a single set of primer. Therefore it is worth to understand the hotspot region in TP53 for initiation of screening of TP53 in a resource limited setting such as Sri Lanka. Hotspot 

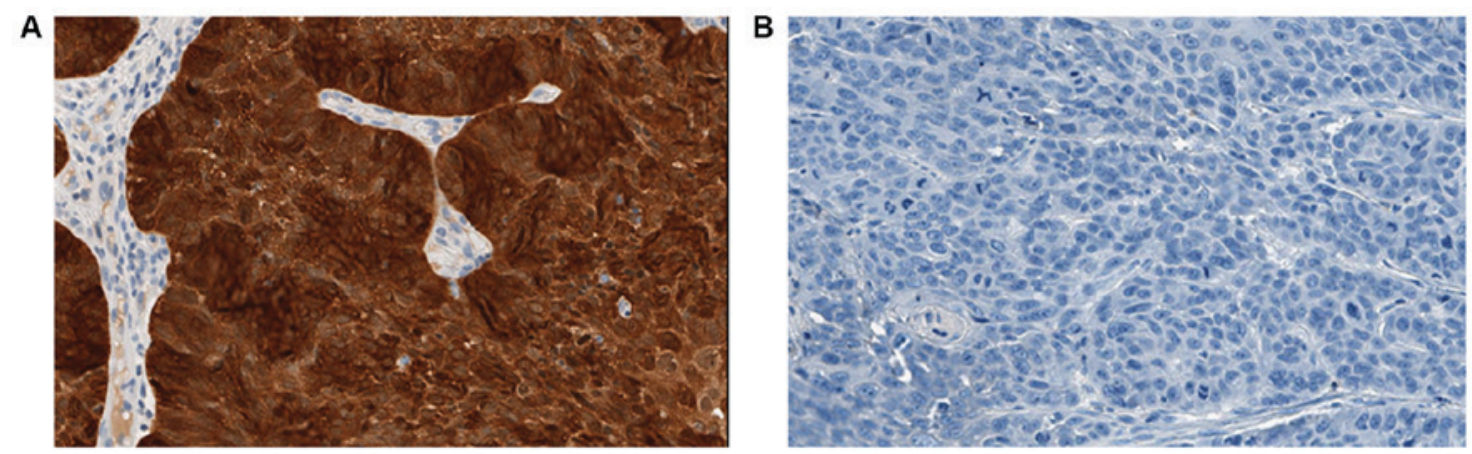

Figure 4. Detection of p16 expression using Ventana Benchmark XT Automated immunohistochemistry/in situ hybridization slide staining system. (A) Positive control showing positive staining of nuclei and cytoplasm. (B) A study sample with negative staining. Magnification, x20.

regions of TP53 identified in the present study are similar to those reported for other ethnic groups. This is also supported by the data in the 'IARC TP53 database' (http://p53.iarc. fr/TP53SomaticMutations.aspx) and 'cBioPortal for cancer genomics' (http://www.cbioportal.org/).

Among the pathogenic variants found, the frameshift variant c.298delC and in-frame variant c.626_637delGAAACACTTTTC have not been previously reported. The c.646G $>\mathrm{C}$ somatic missense variant is reported only in the IARC TP53 database, but the details are not provided. c.383delC and c.576G $>\mathrm{C}$ are novel variants in $\mathrm{HNCs}$, as they have been reported only in the COSMIC database for breast and stomach tumours respectively. Although c. $422 \mathrm{G}>\mathrm{T}$, c. $455 \mathrm{C}>\mathrm{T}$, c. $467 \mathrm{G}>\mathrm{A}$, c. $747 \mathrm{G}>\mathrm{T}$ and c. $818 \mathrm{G}>\mathrm{A}$ have been commonly reported for many types of cancer, these variants have not been reported in HNC or oesophageal cancer.

Some mutations of TP53 such as frame shift deletions or insertions and nonsense or splice site mutations are recessive and require loss of the remaining normal allele for cells to lose p53 tumour suppressor function. However, some point missense mutant forms can have a dominant-negative effect (DNE) because they are no longer recognised by their negative regulator MDM2 and accumulate in the cell to a much greater level than the normal wild-type TP53 allele. These so-called 'dominant-negative' forms of mutant p53 nevertheless have lost their normal transcriptional activity. Loss of function of each identified variant in the current study was assessed based on the reported loss of transcriptional activity data available in the IARC and other databases. Overall transcriptional activity of 2314 distinct mutant proteins has been experimentally measured on a panel of p53-response elements of promoters of downstream transcriptional target genes such as CDKN1A (p21), MDM2 and $B A X$ (23-25). In addition sequence variants have also been evaluated using a computational geometry approach called Delaunay Tessellations to predict the functional impact (26). DNE of sequence variants has been assessed based on studies carried out on promoters of $p 21^{W A F}$, Ribosomal Gene Clusters, etc. (24). Out of ten pathogenic missense variants reported in our study cohort, nine (c.455C $>\mathrm{T}, \mathrm{c} .524 \mathrm{G}>\mathrm{A}$, c. $578 \mathrm{~A}>\mathrm{G}$, c. $583 \mathrm{~A}>\mathrm{T}$, с. $659 \mathrm{~A}>\mathrm{G}$, c. $646 \mathrm{G}>\mathrm{C}$, с. $747 \mathrm{G}>\mathrm{T}$, c. $818 \mathrm{G}>\mathrm{A}$ and c. $844 \mathrm{C}>\mathrm{T}$ ) are predicted to involve complete loss of transcriptional function based on databases compiled from both yeast assay and computational method.

Codon 72 variant (p.Arg72Pro) in exon 4 is a well-known polymorphism present in the normal human population. The implication of this polymorphism in cancer risk and prognosis is controversial, with some earlier studies reporting that p53 protein containing the codon 72 Arginine form has a greater apoptotic potential (27-31) while others have failed to replicate these findings $(32,33)$. In the present study neither the p.Arg72Pro alleles was significantly associated with cancer.

One previous study of TP53 carried out in 1998 on 23 oral squamous cell carcinoma from Sri Lankan patients has been published. This reported nine sequence variants: Missense variant in codons $135,164,176,245,248$; deletions in codons $130,144-148,172-187$ and one insertion in codon 250 (34). None of these variants were found in the current study, which included 19 patients with oral squamous cell carcinoma. However studies done in all subset of HNC in India and Japan showed 21 and $11.6 \%$ of pathogenic TP53 variant and 69 and $13.7 \%$ of HPV positivity respectively $(16,17)$.

Generally, for head and neck cancers without HPV infection has a higher prevalence of TP53 mutation. However, the lower percentage of TP53 mutations was observed in the current study is due to the inclusion of thyroid cancer in the studied cohort as it is considered under head and neck cancer in Sri Lankan context. In the current study, out of 44 patients, 9 patients were with thyroid carcinoma and none of them carried any pathogenic TP53 variants, which may be the possible reason for a decreased percentage of TP53 mutation prevalence $(35,36)$.

TP53 mutations can be classified as disruptive and non-disruptive based on the location and type of mutations. Disruptive mutations are missense mutations located in the DNA-binding domain, or stop codons in any region which create truncated proteins. Non-disruptive mutations are missense mutations located outside the DNA binding domain. Disruptive mutations are closely associated with poor prognosis of head and neck cancer (37) and all the reported pathogenic somatic TP53 mutations in the current study are associated with poor prognosis.

However, we also analysed the pathogenic missense mutations with a computational approach called evolutionary action or EAp53, which has been validated both in vivo and in vitro, for TP53 mutation classification (http://mammoth.bcm.tmc. edu/EAp53/). This approach assigns an evolutionary action score and classifies each p53 missense mutation as either highor low-risk. According to Neskey et al (38), patients with high risk TP53 mutations show poor survival with high invasive and aggressive tumour behaviour. According to the EAp53 analysis c. $422 \mathrm{G}>\mathrm{T}$, c. $455 \mathrm{C}>\mathrm{T}$, c. $524 \mathrm{G}>\mathrm{A}$, c. $578 \mathrm{~A}>\mathrm{G}$, c. $747 \mathrm{G}>\mathrm{T}$ were 
categorized as high risk mutations and c.583A $>$ T, c.646G $>C$, c. $659 \mathrm{~A}>\mathrm{G}, \mathrm{c} .818 \mathrm{G}>\mathrm{A}, \mathrm{c} .844 \mathrm{C}>\mathrm{T}$ as low risk mutations. In addition all truncating mutations are also considered to have poor prognosis.

Generally wild-type p53 protein has very short half-life in the cells under normal conditions due to constant degradation by the MDM2-mediated negative feedback loop (39). In the case of mutant p53 protein, MDM2 protein cannot be induced, thus MDM2-mediated negative feedback is absent leading to accumulation of mutant p53 (40). It is also reported that a contribution to the stabilization of mutant p53 is due to impaired ubiquitination (41). All the missense variations identified in the current study showed the accumulation of p53 protein with the Pattern-A strong immunostaining. However the converse was not true, as there were two samples with Pattern-A IHC which showed no detectable variations in sequence. But these two samples have only $<10 \%$ of tumour cells in the sections used for immunostaining which would have been below the sensitivity of detection by sanger sequencing.

All the truncated proteins that resulted either from frameshift or nonsense variations showed immuno-negativity. The antibody used to detect the expression of p53 protein is DO-7 which binds to the p53 protein between amino acid 1-45 (42). Even though all four truncated protein are longer than 123 amino acids, they remained undetectable. This may be due to nonsense-mediated decay of mRNA with premature stop codon may have resulted in less stable truncated proteins.

All the samples $(\mathrm{N}=4)$ with Pattern-B IHC were TP53 wild-type and, there were $57 \%$ (8/14) of the wild-type samples that showed no positive immuno-reactivity. Thus IHC analysis cannot be used as a standalone method to detect the alteration in p53 as it cannot differentiate between truncated p53 protein and wild-type p53 protein as both show an immuno-negative IHC pattern.

Cigarette smoking and alcoholism are well known triggers of HNCs. The awareness of these risk factors is higher among Sri Lankans. But despite a reduction in cigarette smoking, the burden of HNC has increased constantly over the years, which prompted us to search for other risk factors.

Betel-quid chewing with tobacco is a common habit among Sri Lankans especially those who are engaged in hard physical work for long hour. Furthermore, there is poor awareness of the harmfulness of this habit. $47.7 \%$ of the patients $(\mathrm{N}=21)$ studied were addicted to betel-quid chewing with tobacco and out of them, nine have TP53 sequence variants conferring an altered protein structure.

HPVs are non-enveloped DNA viruses, containing a double stranded circular DNA which consists of an upstream regulatory region (URR), an early region (E) encoding viral regulatory proteins and a late region (L) encoding viral capsid proteins (43). HPV is an identified cause of HNCs and it is reported that HPV-positive HNCs have a better prognosis (44-46). The high-risk HPV proteins E6, E7 target tumour suppressor proteins p53 and RB respectively. Disruption of the function of p53 and pRB lead to uncontrolled cell division (47). Here we studied the expression of p16 protein which is used as a surrogate marker to identify functionally active HPV infection as it is reciprocally overexpressed due to functional inactivation of pRB by E7 protein $(48,49)$. Several previous studies in other countries reported p16 overexpression in HNC.
The highest (38\%) and lowest (7.8\%) level of p16 expression are reported in the USA, while intermediate levels are reported from India (20\%) and Kenya (14.6\%) (50-53). All samples in our study cohort were negative for p16 staining which may suggest the absence of functionally active HPV infection (54).

In a previous study from Sri Lanka $37.2 \%$ of tumour samples from oral cancer patients were reported to be infected when analysed using HPV DNA typing (18). However in the current study, none of the patients were positive on DNA typing which also indicates the absence or presence of very low concentration of HPV DNA in the tumour samples.

It has also been reported that p53 protein with the Arginine72 polymorphism is efficiently degraded by the E6 protein of HPV 16, thus increasing susceptibility to cancer (55). Nevertheless, there are studies that show no correlation between p.Arg72Pro and HPV related cervical cancers $(56,57)$. Our cohort of HNC patients also showed no correlation between p.Arg72Pro and HPV infection.

Exposure to asbestos due to living in houses with asbestos roofing and exposure to rubber by occupations may also have contributed to mutagenesis of TP53 and carcinogenesis in some patients in the present cohort.

In conclusion, we examined all exons and splicing sites of the TP53 gene in HNC and oesophageal cancers from a cohort of Sri Lankan patients and found a high occurrence of gene alterations including several novel variants. All p53 protein altering variants found were positioned between exons 4-8. Only the point missense variants were associated with strong immuno-positivity, thus limiting the use of IHC in detecting mutation status of $\mathrm{p} 53$. Our cohort of patients did not appear to carry significant levels of HPV infection.

\section{Acknowledgements}

The authors would like to thank Ms Anoma Jayasoma (senior technical officer of the Institute of Biochemistry, Molecular Biology and Biotechnology, University of Colombo, Colombo, Sri Lanka), Ms Chameera Helani (library information assistant of the Institute of Biochemistry, Molecular Biology and Biotechnology, University of Colombo) for their assistance in conducting research at the institute and collecting details of the patients. Ms Gayani Kokila Wijesinghe and Ms Yamuna Wickramasinghe Jayasekera (staff technical officers of Department of Pathology, Faculty of Medicine, University of Colombo) for their assistance in making formalin-fixed paraffin-embedded blocks. Dr Calum Kirk (research technician of Northern Institute for Cancer Research, Newcastle University, Newcastle, UK) for assisting in the immunohistochemistry.

\section{Funding}

The present study was funded by National Research Council, Sri Lanka (grant no. 15-33) and Commonwealth Scholarship Commission of the UK (grant no. LKCN-2015-100).

\section{Availability of data and materials}

The datasets used and/or analysed during the current study are available from the corresponding author on reasonable request. 


\section{Authors' contributions}

VM performed the experiments, contributed to the analysis and interpretation of the data, and drafted the manuscript. EHK, KHT and SDS conceived and designed the study, were involved in the molecular genetic studies, data analysis and interpretation, and the revision of the manuscript. KDS and PA provided clinical expertise, recruited the study participants, and supervised the clinical data and histopathological characterization. JL designed the immunohistochemical and HPV studies, and contributed to the analysis of the sequencing data. All authors read and approved the final manuscript.

\section{Ethics approval and consent to participate}

The present study was approved by the Ethics Review Committee, Faculty of Medicine, University of Colombo, Sri Lanka (EC/14/160). Written informed consent form at the time of enrolment was obtained from each patient.

\section{Patient consent for publication}

Not applicable.

\section{Competing interests}

The authors declare that they have no competing interests.

\section{References}

1. Shah JP and Lydiatt W: Treatment of cancer of the head and neck. CA Cancer J Clin 45: 352-368, 1995.

2. Joshi P, Dutta S, Chaturvedi P and Nair S: Head and neck cancers in developing countries. Rambam Maimonides Med J 5: e0009, 2014.

3. Khan Z, Tönnies J and Müller S: Smokeless tobacco and oral cancer in South Asia: A systematic review with meta-analysis. J Cancer Epidemiol 2014: 394696, 2014.

4. National Cancer Control Programme (NCCP): Cancer Incidence Data Sri Lanka 2010. Edition 12. NCCP, Colombo, pp1-82, 2016.

5. Amarasinghe HK, Usgodaarachchi US, Johnson NW, Lalloo R and Warnakulasuriya S: Betel-quid chewing with or without tobacco is a major risk factor for oral potentially malignant disorders in Sri Lanka: A case-control study. Oral Oncol 46: 297-301, 2010.

6. No authors listed: Sri Lankan declaration on oral cancer, smokeless tobacco and areca nut - Towards a society free of oral cancer. Sri Lanka Dental Journal 45: 27-29, 2015

7. Somatunga LC, Sinha DN, Sumanasekera P, Galapatti K, Rinchen S, Kahandaliyanage A, Mehta FR and Nishirani Lanka JD: Smokeless tobacco use in Sri Lanka. Indian J Cancer 49: 357-363, 2012.

8. World Health Organization - International Agency for Research on Cancer (IARC): IARC Monographs on the Evaluation of Carcinogenic Risks to Humans. Volume 89. IARC, Lyon, pp1-593, 2017.

9. Kreimer AR, Clifford GM, Boyle P and Franceschi S: Human papillomavirus types in head and neck squamous cell carcinomas worldwide: A systematic review. Cancer Epidemiol Biomarkers Prev 14: 467-475, 2005.

10. Deb SP and Deb S: Mutant p53 and MDM2 in cancer. Springer, 2014.

11. Hollstein M, Sidransky D, Vogelstein B and Harris CC: p53 mutations in human cancers. Science 253: 49-53, 1991.

12. Chen MB, Wu XY, Yu R, Li C, Wang LQ, Shen W and Lu PH: P53 status as a predictive biomarker for patients receiving neoadjuvant radiation-based treatment: A meta-analysis in rectal cancer. PLoS One 7: e45388, 2012.

13. Fu HL, Shao L, Wang Q, Jia T, Li M and Yang DP: A systematic review of p53 as a biomarker of survival in patients with osteosarcoma. Tumour Biol 34: 3817-3821, 2013.
14. Greenblatt MS, Bennett WP, Hollstein M and Harris CC: Mutations in the p53 tumor suppressor gene: Clues to cancer etiology and molecular pathogenesis. Cancer Res 54: 4855-4878, 1994.

15. Lane DP: On the expression of the $\mathrm{p} 53$ protein in human cancer. Mol Biol Rep 19: 23-29, 1994.

16. Mitra S, Banerjee S, Misra C, Singh RK, Roy A, Sengupta A, Panda CK and Roychoudhury S: Interplay between human papilloma virus infection and p53 gene alterations in head and neck squamous cell carcinoma of an Indian patient population. J Clin Pathol 60: 1040-1047, 2007.

17. Maruyama H, Yasui T, Ishikawa-Fujiwara T, Morii E, Yamamoto Y, Yoshii T, Takenaka Y, Nakahara S, Todo T, Hongyo $\mathrm{T}$ and Inohara $\mathrm{H}$ : Human papillomavirus and p53 mutations in head and neck squamous cell carcinoma among Japanese population. Cancer Sci 105: 409-417, 2014.

18. Jayasooriya PR, Kurose K, Terai M, Sivagnanam K, SiriwardanaS, Tilakaratne WM, Tagami J and Takagi M: Human papillomavirus in oral cancer from Sri Lanka: Prevalence and relationship with clinico-pathological parameters. Oral Med Pathol 8: 45-50, 2003.

19. Miller SA, Dykes DD and Polesky HF: A simple salting out procedure for extracting DNA from human nucleated cells. Nucleic Acids Res 16: 1215, 1988.

20. Richards S, Aziz N, Bale S, Bick D, Das S, Gastier-Foster J, Grody WW, Hegde M, Lyon E, Spector E, et al: Standards and guidelines for the interpretation of sequence variants: A joint consensus recommendation of the American college of medical genetics and genomics and the association for molecular pathology. Genet Med 17: 405-424, 2015.

21. de Roda Husman AM, Walboomers JM, van den Brule AJ, Meijer CJ and Snijders PJ: The use of general primers GP5 and GP6 elongated at their 3' ends with adjacent highly conserved sequences improves human papillomavirus detection by PCR J Gen Virol 76: 1057-1062, 1995.

22. Kim JS and Kim BW: Esophageal cancer and head and neck cancer: The earlier, the better. Gut Liver 9: 131-132, 2015.

23. Bouaoun L, Sonkin D, Ardin M, Hollstein M, Byrnes G, Zavadil J and Olivier M: TP53 variations in human cancers: New lessons from the IARC TP53 database and genomics data. Hum Mutat 37: 865-876, 2016.

24. Petitjean A, Mathe E, Kato S, Ishioka C, Tavtigian SV, Hainaut $P$ and Olivier M: Impact of mutant p53 functional properties on TP53 mutation patterns and tumor phenotype: Lessons from recent developments in the IARC TP53 database. Hum Mutat 28: 622-629, 2007.

25. Kato S, Han SY, Liu W, Otsuka K, Shibata H, Kanamaru R and Ishioka $\mathrm{C}$ : Understanding the function-structure and function-mutation relationships of p53 tumor suppressor protein by high-resolution missense mutation analysis. Proc Natl Acad Sci USA 100: 8424-8429, 2003.

26. Mathe E, Olivier M, Kato S, Ishioka $C$, Vaisman I and Hainaut $P$ : Predicting the transactivation activity of p53 missense mutants using a four-body potential score derived from Delaunay tessellations. Hum Mutat 27: 163-172, 2006.

27. Dumont P, Leu JI, Della Pietra AC III, George DL and Murphy M: The codon 72 polymorphic variants of p53 have markedly different apoptotic potential. Nat Genet 33: 357-365, 2003.

28. Toyama T, Zhang Z, Nishio M, Hamaguchi M, Kondo N, Iwase $\mathrm{H}$, Iwata $\mathrm{H}$, Takahashi S, Yamashita $\mathrm{H}$ and Fujii $\mathrm{Y}$ : Association of TP53 codon 72 polymorphism and the outcome of adjuvant therapy in breast cancer patients. Breast Cancer Res 9: R34, 2007.

29. Damin AP, Frazzon AP, Damin DC, Roehe A, Hermes V, Zettler $\mathrm{C}$ and Alexandre $\mathrm{CO}$ : Evidence for an association of TP53 codon 72 polymorphism with breast cancer risk. Cancer Detect Prev 30: 523-529, 2006.

30. Li T, Lu ZM, Guo M, Wu QJ, Chen KN, Xing HP, Mei Q and Ke Y: 553 codon 72 polymorphism $(\mathrm{C} / \mathrm{G})$ and the risk of human papillomavirus-associated carcinomas in China. Cancer 95: 2571-2576, 2002

31. Fan R, Wu MT, Miller D, Wain JC, Kelsey KT, Wiencke JK and Christiani DC: The p53 codon 72 polymorphism and lung cancer risk. Cancer Epidemiol Biomarkers Prev 9: 1037-1042, 2000.

32. Baynes C, Healey CS, Pooley KA, Scollen S, Luben RN, Thompson DJ, Pharoah PD, Easton DF, Ponder BA and Dunning AM; SEARCH breast cancer study: Common variants in the ATM, BRCA1, BRCA2, CHEK2 and TP53 cancer susceptibility genes are unlikely to increase breast cancer risk. Breast Cancer Res 9: R27, 2007. 
33. Mabrouk I, Baccouche S, El-Abed R, Mokdad-Gargouri R, Mosbah A, Saïd S, Daoud J, Frikha M, Jlidi R and Gargouri A: No evidence of correlation between p53 codon 72 polymorphism and risk of bladder or breast carcinoma in Tunisian patients. Ann NY Acad Sci 1010: 764-770, 2003.

34. Chiba I, Muthumala M, Yamazaki Y, Uz Zaman A, Iizuka T, Amemiya A, Shibata T, Kashiwazaki H, Sugiura C and Fukuda H: Characteristics of mutations in the p53 gene of oral squamous-cell carcinomas associated with betel-quid chewing in Sri Lanka. Int J Cancer 77: 839-842, 1998.

35. Cerami E, Gao J, Dogrusoz U, Gross BE, Sumer SO, Aksoy BA, Jacobsen A, Byrne CJ, Heuer ML, Larsson E, et al: The cBio cancer genomics portal: An open platform for exploring multidimensional cancer genomics data. Cancer Discov 2: 401-404, 2012.

36. Gao J, Aksoy BA, Dogrusoz U, Dresdner G, Gross B, Sumer SO, Sun Y, Jacobsen A, Sinha R, Larsson E, et al: Integrative analysis of complex cancer genomics and clinical profiles using the cBioPortal. Sci Signal 6: pl1, 2013.

37. Poeta ML, Manola J, Goldwasser MA, Forastiere A, Benoit N, Califano JA, Ridge JA, Goodwin J, Kenady D, Saunders J, et al: TP53 mutations and survival in squamous-cell carcinoma of the head and neck. N Engl J Med 357: 2552-2561, 2007.

38. Neskey DM, Osman AA, Ow TJ, Katsonis P, McDonald T, Hicks SC, Hsu TK, Pickering CR, Ward A, Patel A, et al: Evolutionary action score of TP53 identifies high-risk mutations associated with decreased survival and increased distant metastases in head and neck cancer. Cancer Res 75: 1527-1536, 2015.

39. Reich NC, Oren M and Levine A: Two distinct mechanisms regulate the levels of a cellular tumor antigen, p53. Mol Cell Biol 3: 2143-2150, 1983

40. Blagosklonny MV: Loss of function and p53 protein stabilization. Oncogene 15: 1889-1893, 1997.

41. Nagata Y, Anan T, Yoshida T, Mizukami T, Taya Y, Fujiwara T, Kato $\mathrm{H}$, Saya $\mathrm{H}$ and Nakao M: The stabilization mechanism of mutant-type p53 by impaired ubiquitination: The loss of wild-type p53 function and the hsp90 association. Oncogene 18: 6037-6049, 1999.

42. Vojtěsek B, Bártek J, Midgley CA and Lane DP: An immunochemical analysis of the human nuclear phosphoprotein $\mathrm{p} 53$. New monoclonal antibodies and epitope mapping using recombinant p53. J Immunol Methods 151: 237-244, 1992.

43. Harden ME and Munger K: Human papillomavirus molecular biology. Mutat Res Rev Mutat Res 772: 3-12, 2017.

44. Ang KK, Harris J, Wheeler R, Weber R, Rosenthal DI, Nguyen-Tân PF, Westra WH, Chung CH, Jordan RC, Lu C, et al: Human papillomavirus and survival of patients with oropharyngeal cancer. N Engl J Med 363: 24-35, 2010.

45. Lassen P, Eriksen JG, Hamilton-Dutoit S, Tramm T, Alsner J and Overgaard J: Effect of HPV-associated p16INK4A expression on response to radiotherapy and survival in squamous cell carcinoma of the head and neck. J Clin Oncol 27: 1992-1998, 2009.
46. Fakhry C, Westra WH, Li S, Cmelak A, Ridge JA, Pinto H, Forastiere A and Gillison ML: Improved survival of patients with human papillomavirus-positive head and neck squamous cell carcinoma in a prospective clinical trial. J Natl Cancer Inst 100: 261-269, 2008.

47. Dok R and Nuyts S: HPV positive head and neck cancers: Molecular pathogenesis and evolving treatment strategies. Cancers (Basel) 8: E41, 2016.

48. Grønhøj Larsen C, Gyldenløve M, Jensen DH, Therkildsen MH, Kiss K, Norrild B, Konge L and Von Buchwald C: Correlation between human papillomavirus and p16 overexpression in oropharyngeal tumours: A systematic review. Br J Cancer 110: $1587-1594,2014$.

49. Lewis JS Jr, Thorstad WL, Chernock RD, Haughey BH, Yip JH, Zhang Q and El-Mofty SK: p16 positive oropharyngeal squamous cell carcinoma: An entity with a favorable prognosis regardless of tumor HPV status. Am J Surg Pathol 34: 1088-1096, 2010.

50. Smith EM, Rubenstein LM, Hoffman H, Haugen TH and Turek LP: Human papillomavirus, p16 and p53 expression associated with survival of head and neck cancer. Infect Agent Cancer 5: 4, 2010.

51. Murthy V, Swain M, Teni T, Pawar S, Kalkar P, Patil A, Chande A, Ghonge S, Laskar SG, Gupta T, et al: Human papillomavirus/p16 positive head and neck cancer in India: Prevalence, clinical impact, and influence of tobacco use. Indian J Cancer 53: 387-393, 2016.

52. Githaiga BK, Muchiri LW and Rogena EA: P16 expression in subsets of head and neck squamous cell carcinoma reported in Kenyatta National Hospital Nairobi, Kenya. Pathol 46: S96, 2014.

53. Tomczak K, Czerwińska $\mathrm{P}$ and Wiznerowicz M: The cancer genome atlas (TCGA): An immeasurable source of knowledge. Contemp Oncol (Pozn) 19: A68-A77, 2015.

54. Sritippho T, Pongsiriwet S, Lertprasertsuke N, Buddhachat K, Sastraruji T and Iamaroon A: p16-a possible surrogate marker for high-risk human papillomaviruses in oral cancer? Asian Pac J Cancer Prev 17: 4049-4057, 2016.

55. Storey A, Thomas M, Kalita A, Harwood C, Gardiol D, Mantovani F, Breuer J, Leigh IM, Matlashewski G and Banks L: Role of a p53 polymorphism in the development of human papillomavirus-associated cancer. Nature 393: 229-234, 1998.

56. Klug SJ, Wilmotte R, Santos C, Almonte M, Herrero R, Guerrero I, Caceres E, Peixoto-Guimaraes D, Lenoir G, Hainaut P, et al: TP53 polymorphism, HPV infection, and risk of cervical cancer. Cancer Epidemiol Biomarkers Prev 10: 1009-1012, 2001.

57. Andersson S, Rylander E, Strand A, Sällström J and Wilander E: The significance of p53 codon 72 polymorphism for the development of cervical adenocarcinomas. Br J Cancer 85: 1153-1156, 2001.

This work is licensed under a Creative Commons Attribution 4.0 International (CC BY-NC 4.0) License 